- un gène de GAL4 placé sous le contrôle d'un promoteur actif, et un gène «rapporteur» (par exemple celui de la chloramphénicol acétyltransférase) placé sous le contrôle de séquences de contrôle d'un gène de mammifère; séquences auxquelles a été ajouté l'élément UAS. Il est aussi possible de remplacer la région $\mathrm{E} d u$ récepteur des œstrogènes (région de fixation de l'hormone jouant également un rôle dans l'activation transcriptionnelle) par la région C-terminale acide de GAL 4 tout en conservant l'activation transcriptionnelle des gènes en amont desquels se fixe cette molécule hybride [4]. Il est ainsi clair que la spécificité structurale requise pour que la protéine fixée à un site enhancer active la transcription est faible, ressemblant bien plus à celle du bouton qu'à celle de la clé.

On peut rapprocher de ces résultats ceux récemment rapportés de l'activation de promoteurs de levures par les produits des oncogènes fos et $m y c$ fixés en un site d'ADN en amont du promoteur [5]. Là encore des protéines hybrides sont fabriquées, comportant l'essentiel de la séquence des oncogènes, associée à un site de fixation à l'ADN. Compte tenu de la grande diversité des séquences protéiques capables, dans de telles conditions, d'activer la transcription [3, 4], il n'est d'ailleurs pas évident que ces observations soient sûrement transposables au mode d'action réel des oncogènes fos et $m y c$ !

A.K. 1. Ma J, Ptashne M. A new class of yeast
transcriptional activators. Cell $1987 ; 51: 113$ 9.

2. Gill G, Ptashne M. Mutants of GAL 4 protein altered in an activation function. Cell $1987 ; 51: 121-6$.

3. Kakidani H, Ptashne M. GAL 4 activates gene expression in mammalian cells. Cell $1988 ; 52: 161-7$.

4. Webster N, Jin JR, Green S, Hollis M, Chambon $P$. The yeast $\mathrm{UAS}_{6}$ is a transcriptional enhancer in human hela cells in the presence of the GAL 4 transactivator. Cell $1988 ; 52: 169-78$.

5. Lech K, Anderson K, Brent R. DNA-bound

Fos proteins activate transcription in yeast.

\title{
L'amylose vasculaire cérébrale au cours du vieillissement dérive de la protéine $\beta$
}

En utilisant un anticorps spécifique, Coria et al.[1] ont montré que la substance amyloïde qui caractérise l'angiopathie cérébrale amyloïde, sporadique (ACAS) et au cours du vieillissement, est constituée d'une protéine dont les caractères antigéniques sont identiques à ceux de la protéine $\beta$ (qui compose la substance amyloïde de la maladie d'Alzheimer et de l'hémorragie cérébrale héréditaire de type Néerlandais). La séquence des dix derniers acides aminés est identique à celle de la protéine $\beta$; l'anticorps employé était dirigé contre un peptide de 28 acides aminés correspondant à l'extrémité amino-terminale de cette protéine.

Ces différentes maladies se distinguent par la distribution de l'amylose dans le cerveau : dans la maladie d'Alzheimer, les fibrilles amylö̈des se déposent dans les parois vasculaires, dans l'espace extracellulaire du parenchyme cérébral (sous forme de plaques) et dans les neurones; dans l'ACAS, l'atteinte vasculaire prédomine. Les plaques sont plus nombreuses au cours du vieillissement; on sait que le nombre de plaques est corrélé au développement et au degré de la démence dans la maladie d'Alzheimer. En revanche, les accidents hémorragiques sont favorisés par l'atteinte vasculaire prédominante. L'angiopathie cérébrale amyloïde est découverte dans $8 \%$ des autopsies faites entre 70 et 80 ans et dans $60 \%$ des cas chez les centenaires; elle est souvent asymptomatique. Mais elle peut favoriser la survenue d'hémorragies cérébrales hémisphériques, localisées à la substance blanche sous-corticale des lobes cérébraux; ces faits sont connus depuis longtemps des neurologues comme le rappelle un Case Record récent du Massachusetts General Hospital [2]; le diagnostic d'angiopathie cérébrale amyloïde doit être évoqué devant une hémorragie cérébrale, parfois récidivante, chez un sujet âgé non hypertendu.

Les mécanismes qui conduisent à la synthèse de la protéine $\beta$, à sa dégradation et à son agrégation pour former le dépôt amyloïde et pour en déterminer la localisation, sont mal connus. A cet égard, on peut indiquer que l'ARN messager codant pour le précurseur de la protéine $\beta$ est détecté dans le cerveau, mais également dans d'autres tissus comme le thymus humain et chez le foetus, dans le rein, le cœur et la rate [3, 4]. La maladie d'Alzheimer et les autres amyloses cérébrales sont-elles des maladies «plus systémiques»? La question mérite d'être posée.

J.-P. G.

1. Coria F, Castano EM, Frangione B. Brain amyloid in normal aging and cerebral amyloid angiopathy is antigenically related to Alzheimer's disease $\beta$-protein. Am J Path 1987; 129 : 422-8.

2. Kase CS, Vonsattel JP. Case record of the Massachusetts General Hospital. A 73-yearold hypertensive man with intracranial hemorrhages 15 months apart. N Engl J Med $1988 ; 318: 623-31$.

3. Goldgaber D, Lermann MJ, Mc Bride OW, Saffiotti U, Gajdusek DC. Characterization and chromosomal localization of a DNA encoding brain amyloid of Alzheimer's disease. Science 1987 ; 235 : 877-80.

4. Tanzi RE, Gusella JF, Watkins PC, et al. Amyloïd $\beta$-protein gene : cDNA, mRNA distribution, genetic linkage near the Alzheimer locus. Science 1987 ; 235 : 880-4. 